\title{
Food intake in Slovenian adolescents and adherence to the Optimized Mixed Diet: a nationally representative study
}

\author{
Helena Kobe ${ }^{1}$, Matevž Štimec ${ }^{1}$, Cirila Hlastan Ribič ${ }^{2,3}$ and Nataša Fidler Mis ${ }^{1, *}$ \\ 'Dietetics and Nutrition Unit, University Children's Hospital, Bohoričeva 20, SI-1525 Ljubljana, Slovenia: \\ ${ }^{2}$ Chronic Diseases Prevention Centre CINDI, National Institute of Public Health, Ljubliana, Slovenia: ${ }^{3}$ Medical \\ Faculty, Department of Public Health, University of Ljubljana, Ljubljana, Slovenia
}

Submitted 20 July 2010: Accepted 9 September 2011: First published online 24 0ctober 2011

\begin{abstract}
Objectives: To investigate the food intake of Slovenian adolescents and to compare it with food-based dietary guidelines developed for children and adolescents, named the Optimized Mixed Diet (OMD). The OMD is a useful tool for the evaluation of food intake of adolescents.

Design: All adolescents completed an FFQ at a regional health centre; a subgroup also completed a $3 \mathrm{~d}$ weighed dietary protocol at home.

Setting: This study is a part of the first national representative study on the dietary habits of Slovenian adolescents.

Subjects: This cross-sectional study included a representative sample of 2813 Slovenian adolescents entering high school, aged 14-17 years, from all ten geographical regions of Slovenia.

Results: The greatest deviations from the recommended intakes of the main food groups in the OMD were significantly lower intakes of $(P<0 \cdot 001$, mean): vegetables (179 and $163 \mathrm{~g} / \mathrm{d}$ in boys and girls, respectively), bread/cereals (271 and $226 \mathrm{~g} / \mathrm{d}$ ), potatoes/rice/pasta (212 and $163 \mathrm{~g} / \mathrm{d})$ ) in boys also a significantly lower intake of fruits (mean: $321 \mathrm{~g} / \mathrm{d}, P<0 \cdot 001$ ) and a significantly higher intake of meat/meat products (mean: $126 \mathrm{~g} / \mathrm{d}, P<0 \cdot 001$ ). Additionally, the results show too high intake of sugar-sweetened beverages and too low intakes of fish and plant oils in both genders.

Conclusions: The food intake pattern of Slovenian adolescents deviates markedly from a healthy eating pattern. Nutrition education and interventions are needed for Slovenian adolescents.
\end{abstract}

Keywords
Adolescents
Slovenia
FFQ
Food-based dietary guidelines
Food intake be considered, as well as the fact that eating is also connected with many pleasures and serves a variety of social and cultural functions ${ }^{(4)}$. Some European countries, e.g. Holland, Germany and Austria, have introduced FBDG for their populations ${ }^{(5-7)}$. In the USA, FBDG have been introduced in the form of a Food Guide Pyramid ${ }^{(8)}$. The Research Institute of Child Nutrition (Forschungsinstitut für Kinderernährung, Dortmund, Germany) developed FBDG for German children and adolescents. The FBDG have further developed to become to a total diet concept named the Optimized Mixed Diet (OMD) ${ }^{(6,9)}$.

Until now, there have been no reliable data on the food intake of adolescents in Slovenia. Neither have FBDG been developed. We aimed to evaluate the food intake of Slovenian adolescents and compare it with the OMD. The OMD is based on the D-A-CH (D-German, A-Austrian, CH-Swiss) Reference Values for Nutrient Intake ${ }^{(10)}$, which have been adopted and used as the official values in Slovenia since $2004^{(11)}$. 


\section{Methods}

The present study is a part of a larger cross-sectional project designed to investigate the dietary habits of Slovenian adolescents, their goitre prevalence (thyroid size and volume, urinary iodine excretion, dietary iodine intake) and anthropometric measurements ${ }^{(12,13)}$. The investigation took place in ten geographical regions of Slovenia during regular systematic medical examinations from February 2003 until April 2005.

The study sample included $10 \%$ of adolescents entering high school ( $n$ 2813) and is representative of the whole of Slovenia. Adolescents were selected from various high school educational programmes and from all socio-economic groups. Examinations were performed independently in health centres. The number of adolescents from each region was proportional to the number of inhabitants in that region, with adolescents being consecutively recruited at their medical examination, until the specific number for that particular region was reached. All of the information gathered, procedures performed and questionnaires were standardized before the examination.

Written informed consent was obtained from all adolescents prior to their inclusion in the study, which was performed in accordance with the ethical standards specified in the appropriate version of the 1994 Declaration of Helsinki and approved by the Ethical Committee of the Medical Faculty of the University of Ljubljana (No. 84/06/02).

To evaluate the dietary habits, we adopted a semi-quantitative FFQ from Harvard University, which was developed by Willett ${ }^{(14)}$ and also described by Thompson and Byers ${ }^{(15)}$. Several versions of FFQ have been developed at Harvard University and numerous validation studies have been reported $^{(15)}$. The version of the FFQ used in the present study was adjusted and included foods which are commonly consumed in Slovenia. It covered a period of the previous one year. Adolescents were recruited in different seasons and each adolescent completed the FFQ once. The FFQ contained eighty-two food items, could be filled in within $15 \mathrm{~min}$ and has been precisely described previously ${ }^{(13)}$. In short, nine categories were available to report the frequency of consumption of a specific food item (from never or $<1 /$ month to $\geq 6 / d$ ). Foods and salt were categorized into nine groups: (i) milk/milk products; (ii) meat/meat products; (iii) fish/fish products; (iv) oils/fats; (v) starch foods; (vi) vegetables; (vii) fruits; (viii) beverages; and (ix) salt (questions about all types of table salts sold in Slovenia). Adolescents completed the FFQ before the medical examination. Exact instructions were written on the first page of the FFQ and were also given orally by the medical personnel.

Of the 2813 recruited adolescents, 95\% ( $n$ 2661) agreed to complete the FFQ. In order to only evaluate reliable FFQ, $4 \%$ of adolescents ( $n 96$ ) were excluded because of four or more invalid answers on the frequency of consumption (missing frequency, multiple marks for frequency). We also excluded $2 \%$ of adolescents ( $n 54$ ) due to extremely high (more than three standard deviations above the mean) or extremely low (boys $<143 \mathrm{~kJ} / \mathrm{d}$; girls $<119 \mathrm{~kJ} / \mathrm{d}$ ) reported energy intake. Such energy intake was clearly a consequence of inattention or carelessness in reporting, as it deviated exceedingly from the majority and could not represent an average energy intake during the whole year. Excluding these adolescents did not affect the results of the study, since the mean values remained the same. In order to have a more homogeneous age range for facilitating the comparison with the OMD, we also excluded $8 \%$ of adolescents ( $n$ 207) due to age $<15$ years and $3 \%$ of adolescents ( $n 80)$ due to age $>16$ years, as this age is not typical for entering high school in Slovenia. Finally, 2224 adolescents ( $83 \%$ of adolescents with the FFQ), 1010 boys and 1214 girls, aged 15-16 years were included in the analysis.

A subgroup of 197 adolescents was asked to keep a $3 \mathrm{~d}$ weighed dietary protocol (3DP) at home, as a reference standard, after the FFQ administration. Adolescents were individually instructed both orally, by a dietitian at the Centre for Nutrition at the University Children's Hospital in Ljubljana, and by written instructions. These instructions provided information on how to conduct the dietary protocol, how to record accurate amounts and type of all consumed foods, beverages and table salt, how to write recipes for foods cooked and how to specify the brands of foods. Ninetyseven per cent of adolescents correctly completed the 3DP.

Anthropometric measurements were taken by the medical personnel during a clinic examination. Standing height (without shoes) was measured to the nearest $0 \cdot 1 \mathrm{~cm}$ with a stadiometer; body weight was measured in light clothes with a calibrated mechanical balance to the nearest $0 \cdot 1 \mathrm{~kg}$. BMI was calculated as weight in kilograms divided by square of the height in metres.

The FFQ and the 3DP were coded and the results centrally analysed by experienced nutritionists at the Centre for Nutrition at the University Children's Hospital Ljubljana, using the nutrition database software Prodi $5 \cdot 2$ Expert (Wissenschaftliche Verlagsgesellschaft, Stuttgart, Germany). This program is based on the German nutrient survey consisting of: (i) Bundeslebensmittelschlüssel, version II 3, Berlin, 1999 (about 1600 food items); (ii) Souci, Fachmann, Kraut, Nährwerttabellen, Stuttgart, 2000 (about 900 food items); and (iii) industrial products and dietetic foods (about 6500 food items).

The 3DP was used to evaluate the FFQ in the present study. The portion sizes of foods in the FFQ without natural units (e.g. meat, rice, pasta, potatoes) were adjusted post hoc, as proposed by Willett ${ }^{(14)}$. They were adjusted according to the average portion sizes calculated from the 3DP (for girls and boys separately), which was completed by a subgroup of 197 adolescents, in addition to the FFQ. The portion sizes of foods with natural units (e.g. one apple, one cup of milk) remained as they had in the original FFQ.

Absolute intake of foods was calculated from the frequency of consumption (from the FFQ) and the portion size (from the FFQ for foods with natural units and from 
the 3DP for foods without natural units). The energy intake from foods was calculated using the frequency of consumption (from the FFQ), portion size (from the FFQ and 3DP) and energy content of each food item. Energy intake was expressed in $\mathrm{kJ} / \mathrm{d}$ and $\mathrm{kcal} / \mathrm{d}$, with energy density in $\mathrm{kcal} / \mathrm{g}$. Food items were assigned to the same food groups as in the FFQ, with the exception of starch foods, which were separated into bread/cereals, potatoes/rice/pasta and tolerated food groups. Weight from table salt was not added to total food weight. Food and food group intake was expressed in $\mathrm{g} / \mathrm{d}$.

The food intake of Slovenian adolescents was compared with the OMD ${ }^{(6,9)}$.

We used Shapiro-Wilk and Kolmogorov-Smirnov tests to check the normality of the distribution of data. The data (most of the variables) were log transformed. Food intakes were adjusted for energy intake using the residual method $^{(16)}$. We used statistical weighting to standardize the results ${ }^{(17)}$. To test the differences in anthropometric data between genders, the parametric $t$ test was used. A Wilcoxon signed-ranks test was used to compare energy intake, energy density, total food intake and food group intake with the recommendations in the OMD. All data analyses were performed with the SPSS statistical software package version $16 \cdot 0$ (SPSS Inc., Chicago, IL, USA). A two-tailed significance level was taken as $0 \cdot 05$. The results are presented as means with their standard errors.

\section{Results}

Anthropometric measures of Slovenian adolescents included in statistical analyses are listed in Table 1. There were no differences in age and BMI between boys and girls. Boys were on average $9.9 \mathrm{~cm}$ higher $(P<0 \cdot 001)$ and weighed $7 \cdot 8 \mathrm{~kg}$ more than girls $(P<0 \cdot 001)$.

Table 2 presents mean intake of each food subgroup, by gender. Within beverages, water represented $42 \%$ of this group in boys and $47 \%$ in girls, fruit juices and nectars $20 \%$ in boys and girls, followed by syrup beverages, tea, carbonated and low-energy beverages. The majority of vegetables (65\% in boys and $71 \%$ in girls) and fruits (99\% in both boys and girls) were consumed fresh. Boys and girls consumed seven times more bread than cereals. From bread, only $36 \%$ was brown or wholegrain in boys, $40 \%$ in girls. From the

Table 1 Anthropometric measures of Slovenian adolescents aged 15-16 years: nationally representative study, February 2003-April 2005

\begin{tabular}{|c|c|c|c|c|c|c|}
\hline & \multicolumn{2}{|c|}{ Boys ( $n$ 1010) } & \multicolumn{2}{|c|}{ Girls (n 1214) } & \multicolumn{2}{|c|}{ Total (n 2224) } \\
\hline & Mean & SEM & Mean & SEM & Mean & SEM \\
\hline Age (years) & $15 \cdot 7$ & $0 \cdot 1$ & $15 \cdot 6$ & $0 \cdot 1$ & $15 \cdot 6$ & 0.0 \\
\hline Height $(\mathrm{cm})$ & $175 \cdot 7^{*}$ & 0.2 & $165 \cdot 8$ & 0.2 & $170 \cdot 3$ & 0.2 \\
\hline Weight (kg) & $66 \cdot 5^{\star}$ & 0.4 & $58 \cdot 7$ & 0.3 & $62 \cdot 2$ & 0.2 \\
\hline BMI $\left(\mathrm{kg} / \mathrm{m}^{2}\right)$ & $21 \cdot 5$ & $0 \cdot 1$ & $21 \cdot 3$ & $0 \cdot 1$ & $21 \cdot 4$ & $0 \cdot 1$ \\
\hline
\end{tabular}

Mean values were significantly different from those in girls: ${ }^{\star} P<0.001$. group potatoes/rice/pasta, potatoes were the most consumed subgroup, representing $38 \%$ and $44 \%$ of this group in boys and girls respectively, followed by pasta (of which

Table 2 Daily intakes of food subgroups by Slovenian adolescents ( $n$ 2224) aged 15-16 years: nationally representative study, February 2003-April 2005

\begin{tabular}{|c|c|c|c|c|}
\hline \multirow[b]{2}{*}{ Food subgroup $(\mathrm{g} / \mathrm{d})$} & \multicolumn{2}{|c|}{ Boys ( $n$ 1010) } & \multicolumn{2}{|c|}{ Girls ( $n$ 1214) } \\
\hline & Mean & SE & Mean & SE \\
\hline \multicolumn{5}{|l|}{ 1. Beverages } \\
\hline Drinking water & 505 & 14 & 662 & 14 \\
\hline Fruit juices, nectarst & 308 & 10 & 353 & 10 \\
\hline Syrup beverages & 202 & 9 & 204 & 9 \\
\hline Teał & 165 & 7 & 206 & 8 \\
\hline Mineral water & 144 & 8 & 166 & 9 \\
\hline Carbonated beverages & 139 & 7 & 89 & 5 \\
\hline Low-energy beverages & 86 & 6 & 70 & 5 \\
\hline \multicolumn{5}{|l|}{ 2. Vegetables } \\
\hline Fresh vegetables & 116 & 3 & 116 & 3 \\
\hline Cooked vegetables & 63 & 3 & 47 & 2 \\
\hline \multicolumn{5}{|l|}{ 3. Fruits } \\
\hline Fresh fruits & 319 & 9 & 487 & 12 \\
\hline Dried fruits & 2 & 0 & 2 & 0 \\
\hline \multicolumn{5}{|l|}{ 4. Bread/cereals } \\
\hline White bread & 151 & 4 & 120 & 3 \\
\hline Brown, wholegrain bread & 85 & 3 & 79 & 3 \\
\hline Cereals§ & 35 & 2 & 27 & 1 \\
\hline \multicolumn{5}{|l|}{ 5. Potatoes/rice/pasta\| } \\
\hline Potatoes & 81 & 2 & 71 & 2 \\
\hline White pasta & 53 & 2 & 41 & 1 \\
\hline White rice & 31 & 2 & 22 & 1 \\
\hline Legumes & 18 & 1 & 12 & 1 \\
\hline Wholegrain pasta & 15 & 1 & 9 & 1 \\
\hline Wholegrain rice & 14 & 1 & 8 & 1 \\
\hline \multicolumn{5}{|l|}{ 6. Milk/milk products } \\
\hline Whole milk (3.5\% fat) & 202 & 7 & 157 & 5 \\
\hline Whole yoghurt ( $3.5 \%$ fat) & 94 & 3 & 87 & 3 \\
\hline Low-fat milk ( $1 \cdot 6 \%$ fat) & 86 & 7 & 88 & 6 \\
\hline Cheese, cream & 73 & 2 & 71 & 2 \\
\hline Low-fat yoghurt ( $1.6 \%$ fat) & 52 & 2 & 72 & 3 \\
\hline Kefir & 6 & 1 & 4 & 0 \\
\hline \multicolumn{5}{|l|}{ 7. Meat/meat products } \\
\hline Meat & 89 & 2 & 57 & 1 \\
\hline Meat products & 37 & 1 & 28 & 1 \\
\hline 8. Eggstt & $\S \S$ & & |l| & \\
\hline \multicolumn{5}{|l|}{ 9. Fish/fish products } \\
\hline Fish productsłł & 21 & 1 & 21 & 1 \\
\hline Fish & 25 & 1 & 20 & 1 \\
\hline \multicolumn{5}{|l|}{ 10. Oils/fats } \\
\hline Oils & 6 & 0 & 8 & 0 \\
\hline Margarine & 4 & 0 & 4 & 0 \\
\hline Butter & 3 & 0 & 3 & 0 \\
\hline Pork fat & 1 & 0 & 1 & 0 \\
\hline \multicolumn{5}{|l|}{ 11. Tolerated food groups } \\
\hline Pastry, ice cream & 66 & 2 & 77 & 2 \\
\hline Salty snack products & 19 & 1 & 21 & 1 \\
\hline
\end{tabular}

3DP, $3 \mathrm{~d}$ weighed dietary protocol.

Food intakes are adjusted for energy intake.

tOf which, fruit nectars $63 \%$ and $71 \%$ in boys and girls, fruit juices $37 \%$ and $29 \%$ (obtained from the 3DP).

¥Of which, ice tea $73 \%$ and $56 \%$ in boys and girls, tea sweetened with sugar $17 \%$ and $27 \%$, unsweetened tea $10 \%$ and $17 \%$ (obtained from the 3DP). $\S$ Breakfast cereals.

||Cooked cereals including millet, wheat; legumes.

TMilk equivalents: $100 \mathrm{ml}$ milk corresponds to $15 \mathrm{~g}$ hard cheese (e.g. Gouda) or $30 \mathrm{~g}$ soft cheese (e.g. Camembert) or $150 \mathrm{ml}$ cream or $109 \mathrm{ml}$ sour cream. t+Data obtained from the 3DP, does not include eggs in other foods (e.g. pasta, pastry).

¥łTinned fish, fish pâté

$\$ \S 5$. 
Table 3 Daily energy intake, energy density, total foods intake and intake of food groups of Slovenian adolescents $(n 2224)$ aged 15-16 years compared with the OMD ${ }^{(6,9)}$ : nationally representative study, February 2003-April 2005

\begin{tabular}{|c|c|c|c|c|c|c|}
\hline \multirow[b]{3}{*}{ Parameter } & \multicolumn{4}{|c|}{ Diet of Slovenian adolescents } & & \\
\hline & \multicolumn{2}{|c|}{ Boys ( $n$ 1010) } & \multicolumn{2}{|c|}{ Girls (n 1214) } & \multicolumn{2}{|c|}{ OMD recommended values } \\
\hline & Mean & SE & Mean & SE & Boys & Girls \\
\hline \multicolumn{6}{|l|}{ Energy intake } & $15-18$ \\
\hline $\mathrm{kJ}$ & $12736^{*}$ & 216 & $9675^{*}$ & 146 & $13000 \neq \ddagger$ & $10500 \ddagger \ddagger \dagger$ \\
\hline kcal & $3043^{*}$ & 52 & $2312^{*}$ & 35 & $3100 \neq \ddagger$ & $2500 \neq \ddagger$ \\
\hline \multirow[t]{2}{*}{ Energy density (kcal/g) } & $0.94^{*}$ & 0.02 & $0 \cdot 69^{*}$ & $0 \cdot 01$ & 0.78 & $0 \cdot 78$ \\
\hline & \multicolumn{6}{|c|}{ Food amounts $(\mathrm{g} / \mathrm{d})$} \\
\hline Total foods & $3316^{*}$ & 30 & $3508^{*}$ & 29 & 3615 & 3210 \\
\hline \multicolumn{7}{|l|}{ Beverages and plant foods } \\
\hline 1. Beverages & 1549 & 29 & $1750^{*}$ & 28 & 1500 & 1400 \\
\hline 2. Vegetables & $179^{*}$ & 5 & $163^{*}$ & 4 & 350 & 300 \\
\hline 3. Fruits & $321^{*}$ & 9 & $489^{*}$ & 12 & 350 & 300 \\
\hline 4. Bread/cerealst & $271^{*}$ & 4 & $226^{*}$ & 4 & 350 & 280 \\
\hline 5. Potatoes/rice/pastał & $212^{*}$ & 4 & $163^{*}$ & 3 & 280 & 230 \\
\hline \multicolumn{7}{|l|}{ Animal foods } \\
\hline 6. Milk/milk products§ & 513 & 10 & 479 & 9 & 500 & 450 \\
\hline 7. Meat/meat products & $126^{*}$ & 3 & 85 & 2 & 85 & 75 \\
\hline 8. Eggs $\|$ & ब & & tt & & $20 \S \S$ & $20 \S \S$ \\
\hline 9. Fish/fish products & $46^{*}$ & 2 & $41^{*}$ & 1 & 30|||| & 30|||| \\
\hline \multicolumn{7}{|l|}{ High-fat, high-sugar foods } \\
\hline 10. Oils/fats & $14^{*}$ & 0 & $16^{*}$ & 0 & 45 & 40 \\
\hline 11. Tolerated food groups & $85^{\star}$ & 2 & 98 & 2 & $105 \uparrow$ & $85 \uparrow \bigoplus$ \\
\hline
\end{tabular}

OMD, Optimized Mixed Diet; 3DP, 3 d weighed dietary protocol.

Food intakes are adjusted for energy intake.

Mean values were significantly different from those of the OMD (Wilcoxon signed-ranks test): ${ }^{\star} P<0 \cdot 001$.

tBreakfast cereals.

¥Cooked cereals including millet, wheat; legumes.

\$Milk equivalents: $100 \mathrm{ml}$ milk corresponds to $15 \mathrm{~g}$ hard cheese (e.g. Gouda) or $30 \mathrm{~g}$ soft cheese (e.g. Camembert) or $150 \mathrm{ml}$ cream or $109 \mathrm{ml}$ sour cream. ||Data obtained from the 3DP, does not include eggs in other foods (e.g. pasta, pastry).

$\uparrow 5$.

+十8.

¥¥Reference values for nutrient intake assuming moderate physical activity level $(P A L=1 \cdot 75)^{[10]}$.

$\S \S$ Corresponds to 2-3 eggs/week.

||||Fish only (i.e. without fish products), corresponds to 1 portion (100-200 g)/week.

-For example, sugar, sweets, jam, chocolate, cake.

$22 \%$ in boys and $18 \%$ in girls was wholegrain), rice (of which $31 \%$ in boys and $27 \%$ in girls was wholegrain) and legumes. Milk (of which $70 \%$ and $64 \%$, in boys and girls respectively, was whole fat) represented $56 \%$ and $51 \%$ of the group milk/milk products in boys and girls, followed by yoghurt (of which $64 \%$ in boys and 55\% in girls was whole fat), cheese, cream and kefir. The majority of the group meat/meat products was represented by meat $(71 \%$ in boys and $67 \%$ in girls), the rest being meat products such as salami, sausages and pâté. With regard to fish/fish products, it was fish itself which was most often consumed in boys (54\%), whereas fish products (tinned fish, fish pâté) were more prominent in girls (51\%). In the group oils/fats, oils were the most consumed subgroup (43\% in boys and $50 \%$ in girls), followed by margarine, butter and pork fat. Within the tolerated food groups, pastry and ice cream were the most consumed foods ( $78 \%$ in both boys and girls), the rest being salty snack products.

Adolescents reported a significantly lower energy intake $(P<0.001)$ than recommended, i.e. $98 \%$ and $92 \%$ of that in the OMD among boys and girls, respectively. Compared with the OMD, energy density among boys, i.e. $0.94 \mathrm{kcal} / \mathrm{g}$, was significantly higher $(P<0 \cdot 001)$ and total food intake was significantly lower $(P<0 \cdot 001)$. On the contrary, energy density among girls was significantly lower $(P<0 \cdot 001)$, i.e. $0.69 \mathrm{kcal} / \mathrm{g}$, whereas total food intake was significantly higher $(P<0 \cdot 001)$ than that in the OMD (Table 3$)$.

Comparing the mean intakes of the main food groups with the OMD (Table 3), boys consumed adequate amounts of beverages, milk/milk products and tolerated food groups. They did not meet the minimum recommendations $(P<0 \cdot 001)$ for vegetables (179 v. recommended $350 \mathrm{~g} / \mathrm{d})$, fruits $(321 v .350 \mathrm{~g} / \mathrm{d})$, bread/cereals $(271 v .350 \mathrm{~g} / \mathrm{d})$, potatoes/rice/pasta $(212 v .280 \mathrm{~g} / \mathrm{d})$ and oils/fats $(14 v .45 \mathrm{~g} / \mathrm{d})$. However, their consumption of certain food groups was too high $(P<0 \cdot 001)$ : meat $/$ meat products $(126 v .85 \mathrm{~g} / \mathrm{d})$ and fish/fish products (46 v. $30 \mathrm{~g} / \mathrm{d}$ ). Girls had adequate intakes of fruits, milk/milk products, meat/meat products and tolerated food groups, whereas their intakes of vegetables (163 v. $300 \mathrm{~g} / \mathrm{d}$ ), bread/cereals (226 v. $280 \mathrm{~g} / \mathrm{d}$ ), potatoes/rice/pasta $(163 v .230 \mathrm{~g} / \mathrm{d})$ and oils/fats $(16 v .40 \mathrm{~g} / \mathrm{d})$ were too low $(P<0 \cdot 001)$. On the other hand, girls consumed too high amounts of beverages (1750 v. $1400 \mathrm{~g} / \mathrm{d}$; $P<0 \cdot 001)$ and fish/fish products (41 v.30 g/d; $P<0 \cdot 001)$. 
Figures. 1 and 2 depict the percentages of boys and girls respectively who did not achieve or exceeded recommendations for energy intake, energy density, total food intake and intakes of food groups in the OMD.

\section{Discussion}

The present study is the first national representative study on food intake of adolescents in Slovenia. We compared the food intake of Slovenian adolescents with the dietary concept OMD $^{(6,9)}$, which are the FBDG that were developed for German children and adolescents, but are based on the reference values which have been adopted also in Slovenia ${ }^{(10,11)}$. We found that the dietary pattern of Slovenian adolescents differed considerably from the recommendations. The strengths of the present study are: the large number of participants (10\% of Slovenian adolescents entering high school); the very high participation rate (95\%); and the inclusion of adolescents originating

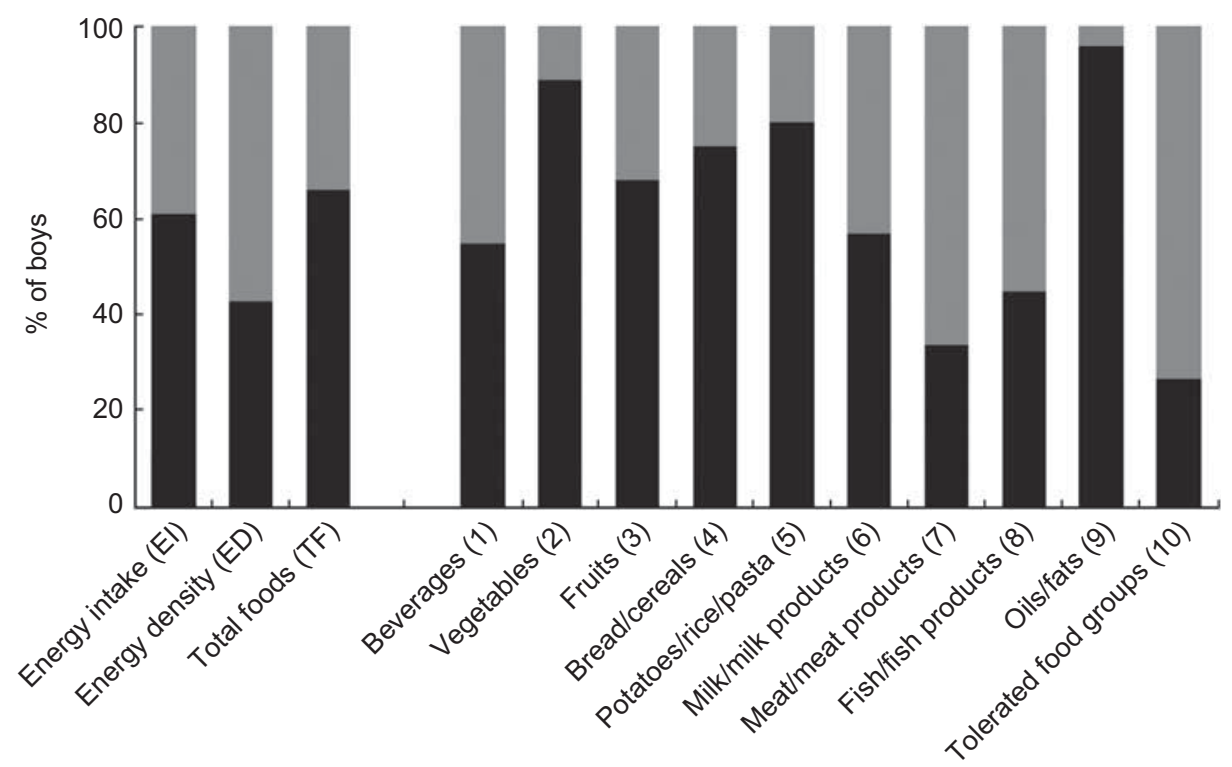

Fig. 1 Percentages of Slovenian adolescent boys ( $n$ 1010) aged 15-16 years who meet $(\square)$ and do not meet ( $\square$ ) the recommendations in the Optimized Mixed Diet $(\mathrm{OMD})^{(6,9)}$ for energy intake, energy density and food intakes: nationally representative study, February 2003-April 2005. OMD recommended values: El, $13000 \mathrm{~kJ}$; ED, $0.78 \mathrm{kcal} / \mathrm{g} ; \mathrm{TF}, 3615 \mathrm{~g} / \mathrm{d} ; 1$, $1500 \mathrm{~g} / \mathrm{d} ; 2$, $350 \mathrm{~g} / \mathrm{d} ; 3,350 \mathrm{~g} / \mathrm{d} ; 4$, $350 \mathrm{~g} / \mathrm{d} ; 5,280 \mathrm{~g} / \mathrm{d} ; 6,500 \mathrm{~g} / \mathrm{d} ; 7,85 \mathrm{~g} / \mathrm{d} ; 8,30 \mathrm{~g} / \mathrm{d} ; 9,45 \mathrm{~g} / \mathrm{d} ; 10,105 \mathrm{~g} / \mathrm{d}$

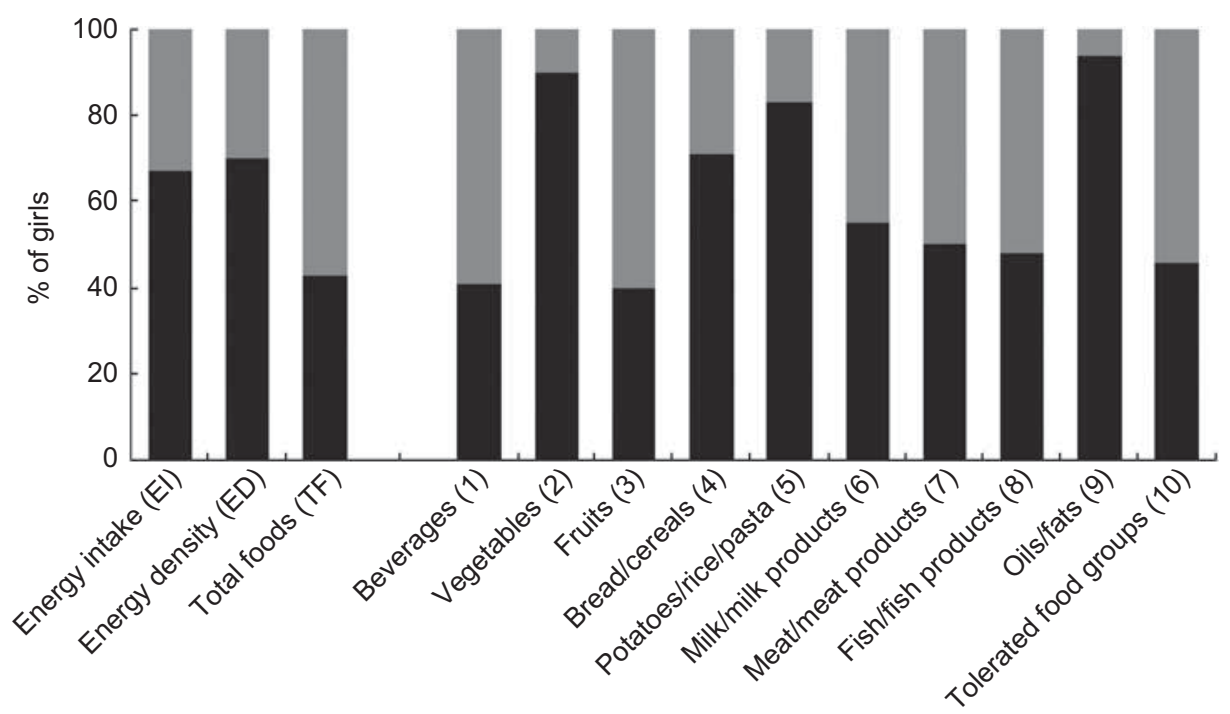

Fig. 2 Percentages of Slovenian adolescent girls ( $n$ 1214) aged 15-16 years who meet $(\square)$ and do not meet ( $\square$ ) the recommendations in the Optimized Mixed Diet $(\mathrm{OMD})^{(6,9)}$ for energy intake, energy density and food intakes: nationally representative study, February 2003-April 2005. OMD recommended values: El, $10500 \mathrm{~kJ}$; ED, $0.78 \mathrm{kcal} / \mathrm{g} ; \mathrm{TF}, 3210 \mathrm{~g} / \mathrm{d} ; 1$, $1400 \mathrm{~g} / \mathrm{d} ; 2,300 \mathrm{~g} / \mathrm{d} ; 3,300 \mathrm{~g} / \mathrm{d} ; 4,280 \mathrm{~g} / \mathrm{d} ; 5,230 \mathrm{~g} / \mathrm{d} ; 6,450 \mathrm{~g} / \mathrm{d} ; 7,75 \mathrm{~g} / \mathrm{d} ; 8,30 \mathrm{~g} / \mathrm{d} ; 9,40 \mathrm{~g} / \mathrm{d} ; 10,85 \mathrm{~g} / \mathrm{d}$ 
from all geographic regions as well as from both urban and rural areas and from all socio-economic groups.

Mean energy intake in adolescents was below the reference values for moderate physical activity (physical activity level $=1 \cdot 75$ ). With respect to normal BMI, it is apparent that physical activity level was rather low. We agree that FBDG should be joined with an appeal for physical activity, to actively stimulate a more healthy lifestyle ${ }^{(3,9)}$. Low energy intake among adolescents of the same age has also been reported in Croatia, Germany, Switzerland, Spain and Turkey ${ }^{(18-22)}$. We also examined the presence of under- and over-reporters in the studied population of adolescents ${ }^{(23)}$, using a method based on the ratio between reported energy intake and predicted BMR (EI:BMR), developed by Goldberg et al. ${ }^{(24)}$. We included the misreporters as well in the processing of data of the present paper, as we adjusted food intakes for energy intake. Therefore the results for food intakes are independent of energy.

Consumption of beverages exceeded the recommendations, although significantly only in girls. Water and tea without sugar (i.e. energy-free beverages) are recommended beverages in the OMD. Fruit juices should only be added to water in small amounts to improve the taste. Girls exceeded the recommendations for beverage intake due to too high intake of sugar-sweetened beverages. We obtained more specific information about consumption of beverages among Slovenian adolescents from the 3DP. Sugar-sweetened beverages (i.e. fruit nectars, syrup beverages, tea sweetened with sugar, ice tea and carbonated beverages) accounted for $44 \%$ of beverages in boys (mean: $683 \mathrm{ml} / \mathrm{d}$ ) and $41 \%$ in girls (mean: $715 \mathrm{ml} / \mathrm{d}$ ). Fruit juices amounted to $7 \%$ of beverages in boys and $6 \%$ in girls. Energy-free beverages (i.e. water, tea without sugar and low-energy beverages with artificial sweeteners) accounted for $49 \%$ of beverages in boys and $53 \%$ in girls.

Many beneficial effects of fruits and vegetables are owing to their high contents of essential nutrients and phytochemicals, low energy density and low glycaemic load. These have a significant role in protection against chronic diseases ${ }^{(25-27)}$. Of major concern in the food intake of Slovenian adolescents is the extremely low intake of vegetables (only $11 \%$ of boys and $10 \%$ of girls consumed the recommended amount). Adolescents were found to eat low amounts of vegetables also in Germany, Norway, Belgium, Central and Eastern Europe ${ }^{(28-31)}$. Actions to improve intake of vegetables are especially required.

Intake of fruits was adequate among Slovenian girls ( $60 \%$ of girls consumed the amount recommended in the OMD or more), but was not sufficient among Slovenian boys (only $32 \%$ of boys achieved recommended intake). Similarly in Australia and Belgium girls consumed more fruits than boys ${ }^{(30,32)}$, although in most studies fruit intake was still too low ${ }^{(28-31,33)}$. On the other hand, high intake of fruits was also shown in a Spanish study, where the majority of young people ate fresh fruits every day ${ }^{(34)}$.
Adolescents in Slovenia consumed insufficient amounts of bread/cereals. Cereals contributed only 13 and $12 \%$ to this group in boys and girls respectively, while bread was mainly consumed as white. This is contrary to the OMD, which recommends at least half of products from this group as whole grains. Intake of potatoes/rice/pasta was insufficient to an even greater extent. According to the OMD, potatoes should mainly be eaten fresh cooked. Whereas we obtained no information from the FFQ about how the potatoes were prepared, we obtained information from the 3DP. Potatoes were consumed mainly cooked (50\%), followed by roasted (22\%), fried (18\%) and baked (10\%). In the OMD, wholegrain rice and pasta are preferred, but Slovenian adolescents consumed more than two-thirds of rice and pasta as white. Our finding of low intake of wholegrain products is similar to that of others ${ }^{(28,35,36)}$ and indicates the need for increased efforts to encourage adolescents to consume more wholegrain foods.

The mean intake of milk/milk products in boys and girls was slightly higher than in the OMD, although the difference was not significant. Despite this, $43 \%$ of boys and $45 \%$ of girls did not meet minimum recommendations for intake of food items from this group. The OMD recommends intake of low-fat milk products with little or no added sugar. Slovenian boys consumed one-third of milk and yoghurt as low-fat varieties, and Slovenian girls one-third of milk and one-half of yoghurt as low-fat varieties. In Slovenia it is recommended that children entering primary school (i.e. at the age of 6 years) should start consuming low-fat milk, which in Slovenia contains $1.6 \%$ of milk fat. In the USA low-fat (i.e. $1 \%$ of milk fat) and fat-free (skimmed) milk and milk products are recommended for all persons at 2 years of age or above $^{(8)}$. More than half of all yoghurts eaten by Slovenian adolescents were fruit yoghurts (data not shown), which usually contain lots of sugar as well as additives.

We found that adolescent boys consumed too much meat/meat products, both boys and girls also too much fish/fish products. Avoiding meat products would help to take steps towards the OMD, as they accounted for onethird of the intake in the meat/meat products group. For fish/fish products, the OMD recommends solely the intake of sea fish, as they are a very rich source of iodine among other nutrients. Slovenian adolescents consumed lots of fish products, which represented about half of the intake of the fish/fish products group. This is the reason why the recommended values of the OMD from $2003^{(9)}$ were exceeded. Newer recommendations ${ }^{(37)}$ have reduced the amount of fish by half (i.e. to $15 \mathrm{~g} / \mathrm{d}$ ), due to the fact that the iodine content of milk and milk products has increased in Germany in recent years ${ }^{(38)}$ and the contribution from fish is not that significant. Among Slovenian adolescents milk and milk products were also found to be an important iodine source ${ }^{(13)}$. In spite of that, in our opinion the recommendation of $30 \mathrm{~g} / \mathrm{d}$ for fish should be maintained for Slovenian adolescents, as sea 
fish are also a very rich source of $n$-3 long-chain PUFA, especially EPA (20:5n-3) and DHA (22: $6 n-3)$, which are important in CVD prevention ${ }^{(39)}$. Meat products and fish products also contribute to excessive salt intake found in Slovenian adolescents ${ }^{(40)}$.

As for oils/fats, the OMD recommends consumption of plant oils, mostly rapeseed oil, as it has favourable effects on serum lipoproteins ${ }^{(41,42)}$. Only $4 \%$ of boys and $6 \%$ of girls achieved recommendations for the oils/fats group and only a half of consumed fats were plant oils.

Slovenian adolescents did not consume too high amounts of the food items from the tolerated food group; boys even had a significantly lower intake than that allowed in the OMD. These foods are not recommended, but are allowed every now and then, to satisfy individuals' taste preferences.

Sugar-sweetened beverages contributed 9\% and 10\% to daily energy intake in Slovenian adolescent boys and girls. The sugar intake could be reduced greatly by avoiding drinking these beverages, since they account for $31 \%$ of total sugar intake in boys and girls. In America, the public health and economic benefits of taxing sugarsweetened beverages have been examined. A tax would reduce the consumption of sugar-sweetened beverages and consequently decrease the risk of chronic diseases. Thus the contribution of unhealthy diets to health-care costs would decrease as well ${ }^{(43,44)}$.

From all of the food groups the major concerns in the diet of Slovenian adolescents are markedly too low intakes of vegetables and oils/fats. Concerning macronutrients and micronutrients, vegetables are the most nutritious food group in the OMD, followed by milk/milk products, bread/cereals and fruits. Recommended intakes of fruits and vegetables could only be achieved by including them in every meal, i.e. five times daily. In cooked meals, potatoes, pasta and/or rice should be increased at the expense of meat dishes ${ }^{(6,9)}$. To achieve a favourable fatty acid composition, adolescents should choose the low-fat varieties of meat/meat products, milk/ milk products, reduce their intake of tolerated foods (i.e. sweets, chocolate), butter and pork fat, and at the same time increase their intakes of sea fish and plant oils, such as rapeseed oil, soya oil, nut oil and fish oil.

The OMD was developed on the basis of the German DONALD (Dortmund Nutritional and Anthropometric Longitudinally Designed) study ${ }^{(45)}$. The findings of that study with respect to the adolescents' intakes of vegetables, bread/cereals, potatoes/rice/pasta, oils/fats, fish, as well as meat/meat products in boys, are similar to findings of the present study. The most outstanding difference between Slovenian and German adolescents is noticed in fruit intake among girls; in German girls it amounted to less than 50\% of that recommended in the OMD, while in Slovenian girls it was higher than that recommended in the OMD.

Some limitations of the present study also have to be considered. As in Slovenia there is no representative database on food composition, we used the composition of the comprehensive German database which is the most widely used in Slovenia. To overcome this weakness, we compared our data with the recommendations developed by Kersting et al. for the paediatric population in Germany. Another limitation is that we used an existing questionnaire, as suggested by Willett ${ }^{(14)}$, since we had neither the time nor the resources for an investment in designing a questionnaire de novo. For evaluation we adjusted the portion sizes. Willett reported that the portion size specification for foods without natural units was sometimes ignored by participants who fill in the FFQ. Marked frequency of consumption in the FFQ would have been the same even if the portion size was different ${ }^{(14)}$. Therefore we checked how the portion sizes from the FFQ in the present study differed from those calculated from the 3DP, separately for boys and girls. Portion sizes for foods without natural units differed considerably, so we replaced and adjusted them post hoc in the FFQ. One further limitation of our study is that we did not include an investigation about the physical activity of adolescents. Moreover, the FFQ used in the study did not include a separate question about egg consumption. Data obtained from the 3DP showed that boys and girls respectively consumed on average 5 and $8 \mathrm{~g}$ eggs/d (not including eggs in other foods, e.g. pasta, pastry), which is much lower than the $20 \mathrm{~g} / \mathrm{d}$ recommended in the OMD.

\section{Conclusions}

In the first national representative study on the dietary intake of Slovenian adolescents we compared the food intake with the diet concept OMD. The OMD has been shown as a useful tool for the evaluation of food intake of adolescents in countries where FBDG have not yet been introduced. The results of the present study indicate that Slovenian adolescents are not meeting the minimum recommendations for vegetables, grains, fish, plant oils, boys additionally for fruits; and that adolescents are exceeding recommendations for fish products and sugarsweetened beverages, boys additionally for meat and meat products. Our findings support the need for nutrition guidance focused on encouraging the consumption of vegetables, fruits, wholegrain varieties of starchy foods, semi-skimmed milk/milk products and plant oils, while preferring no- or low-added-sugar choices of foods and beverages. Nutrition education and interventions are immediately needed for Slovenian adolescents. For the future we suggest for every country to develop and use its own FBDG, to enable the adequate choice of locally available foods. We also suggest making further national representative studies on diet among other age groups in Slovenia, especially infants, children, pregnant and lactating women, and as well as following the time trends in consumption within the adolescent age group. 


\section{Acknowledgements}

The present study was supported by the Ministry of Higher Education, Science and Technology, Ljubljana, Slovenia (project no. J3-4512) and the Ministry of Health, Ljubljana, Slovenia (project no. C2711-08Y000178). The authors have no conflicts of interest. H.K. was involved in data management, analysis of the results, interpretation of the data and drafting of the paper. M.Š. was involved in the design of the study, data management and analysis of the results. C.H.R. was involved in the interpretation of the data, analysis of the results and drafting of the paper. N.F.M. was involved in the conception and design of the study, interpretation of the data, analysis of the results and drafting of the paper. All authors critically reviewed the manuscript and approved the final version submitted for publication. The authors acknowledge and thank Ciril Kržišnik, Andreja Širca-Čampa, Primož Kotnik, Tadej Battelino, Mirjana Zupančič, Mihaela Jurčec and Damjana Podkrajšek for their kind help in organizing and coordinating the study. Many thanks also go to all of the paediatricians involved: Valter Boltar, Polona Brcar, Mira Cajnkar Kac, Nataša Fišer Marčun, Tone Gortnar, Ksenija Goste, Mojca Goršič-Frank, Nives Hočevar, Tanja Horvat, Jasna Jenko, Melanija Kocjan, Janeta Kodrin Pušnik, Ružica Koterle, Marjeta Kuburič, Romana Laktić, Maruška Levstek Plut, Eva Lovše-Perger, Marjeta Maroša Meolic, Mojca Pisanski, Sonja Posega Devetak, Leon Radolli, Darja Srakar Rus, Šarlota Starc, Bojan Štefančič, Majda Troha, Olga Vrbošek, Marjeta Vrhovšek Hribar, Barbara Weibl, Zlatka Zupančič and Marija Žiberna. The authors would also like to thank to Miljana Vegnuti for her assistance with the statistical analysis. Last, but not least, they thank all participating adolescents.

\section{References}

1. Jenkins S \& Horner SD (2005) Barriers that influence eating behaviors in adolescents. J Pediatr Nurs 20, 258-267.

2. Story M, Neumark-Sztainer D \& French S (2002) Individual and environmental influences on adolescent eating behaviors. J Am Diet Assoc 102, 3 Suppl., S40-S51.

3. World Health Organization (1998) Preparation and Use of Food-based Dietary Guidelines. Joint FAO/WHO Expert Consultation. WHO Technical Report Series no. 880. Geneva: WHO.

4. Koletzko B, de la Guéronniére V, Toschke AM et al. (2004) Nutrition in children and adolescents in Europe: what is the scientific basis? Introduction. Br J Nutr 92, 2 Suppl., S67-S73.

5. Löwik MRH, Hulshof KFAM \& Brussaard JH (1999) Foodbased dietary guidelines: some assumptions tested for the Netherlands. Br J Nutr 81, 2 Suppl., S143-S149.

6. Kersting M, Alexy U \& Clausen K (2005) Using the concept of food based dietary guidelines to develop an Optimized Mixed Diet (OMD) for German children and adolescents. J Pediatr Gastroenterol Nutr 40, 301-308.

7. Elmadfa I \& Freisling H (2007) Food-based dietary guidelines in Austria. Ann Nutr Metab 51, 2 Suppl., 8-14.

8. US Department of Agriculture (2005) MyPyramid. Washington, DC: USDA.
9. Kersting M, Alexy U \& Rothman N (2003) Fakten zur Kinderernäbrung. München: Hans Marseille Verlag.

10. German Nutrition Society, Austrian Nutrition Society, Society for Nutrition Researchet al. (2002) Referenzwerte für die Nährstoffzufubr. Frankfurt am Main: Umschau Braus.

11. Delovna skupina za pripravo "Referenčnih vrednosti za vnos hranil" (2004) Referenčne vrednosti za vnos hranil (prevod iz nemškega jezika). Ljubljana: Ministrstvo za zdravje.

12. Kotnik P, Širca-Čampa A, Zupančič M et al. (2006) Goiter prevalence and urinary iodine concentration in Slovenian adolescents. Thyroid 16, 769-773.

13. Štimec M, Fidler Mis N, Smole K et al. (2007) Iodine intake of Slovenian adolescents. Ann Nutr Metab 51, 439-447.

14. Willett WC (editor) (1998) Nutritional Epidemiology. New York: Oxford University Press.

15. Thompson FE \& Byers T (1994) Dietary assessment resource manual. J Nutr 124, 11 Suppl., 2245S-2317S.

16. Willett WC \& Stampfer MJ (1986) Total energy intake: implications for epidemiologic analyses. Am J Epidemiol 124, $17-27$.

17. Statistical Office of the Republic of Slovenia, Ministry of the Interior (2005) Census of Population. Ljubljana: Ministry of the Interior, Internal Administrative Affairs Directorate.

18. Barić IC, Cvjetić S \& Satalić Z (2001) Dietary intakes among Croatian schoolchildren and adolescents. Nutr Health 15, 127-138.

19. Kersting M, Sichert-Hellert W, Lausen B et al. (1998) Energy intake of 1 to 18 year old German children and adolescents. $Z$ Ernahrungswiss 37, 47-55.

20. Clavien H, Theintz G, Rizzoli R et al. (1996) Does puberty alter dietary habits in adolescents living in a western society? J Adolesc Health 19, 68-75.

21. Serra-Majem L, Ribas-Barba L, Perez-Rodrigo C et al. (2006) Nutrient adequacy in Spanish children and adolescents. BrJ Nutr 96, 1 Suppl., S49-S57.

22. Bas M, Altan T, Dinçer D et al. (2005) Determination of dietary habits as a risk factor of cardiovascular heart disease in Turkish adolescents. Eur J Nutr 44, 174-182.

23. Kobe H, Kržišnik C \& Fidler Mis N (2011) Under- and overreporting of energy intake in Slovenian adolescents. J Nutr Educ Behav (Epublication ahead of print version).

24. Goldberg GR, Black AE, Jebb SA et al. (1991) Critical evaluation of energy intake data using fundamental principles of energy physiology: 1 . Derivation of cut-off limits to identify under-recording. Eur J Clin Nutr 45, 569-581.

25. Bazzano LA, Serdula MK \& Liu S (2003) Dietary intake of fruits and vegetables and risk of cardiovascular disease. Curr Atheroscler Rep 5, 492-499.

26. Suter PM \& Moser C (2005) Fruit and vegetable. Ther Umsch 62, 607-610.

27. Pokorn D (2002) The effect of energy density of food on food intake. Zdravstveno varstvo 11/12, 339-341.

28. Kersting M, Alexy U, Kroke A et al. (2004) Nutrition of children and adolescents. Results of the DONALD Study. Bundesgesundheitsblatt Gesundheitsforschung Gesundbeitsschutz 47, 213-218.

29. Andersen LF, Øverby N \& Lillegaard IT (2004) Intake of fruit and vegetables among Norwegian children and adolescents. Tidsskr Nor Laegeforen 124, 1396-1398.

30. Paulus D, Saint-Remy A \& Jeanjean M (2001) Dietary habits during adolescence: results of the Belgian Adolux Study. Eur J Clin Nutr 55, 130-136.

31. Pařízková J (2000) Dietary habits and nutritional status in adolescents in Central and Eastern Europe. Eur J Clin Nutr 54, 1 Suppl., S36-S40.

32. Savige GS, Ball K, Worsley A et al. (2007) Food intake patterns among Australian adolescents. Asia Pac J Clin Nutr 16, 738-746. 
33. Muñoz KA, Krebs-Smith SM, Ballard-Barbash R et al. (1997) Food intakes of US children and adolescents compared with recommendations. Pediatrics 100, 323-329.

34. Farré Rovira R, Frasquet Pons I, Martínez Martínez I et al. (1999) The usual diet of a group of adolescents from Valencia. Nutr Hosp 14, 223-230.

35. Thane CW, Jones AR, Stephen AM et al. (2005) Whole-grain intake of British young people aged 4-18 years. Br J Nutr 94, 825-831.

36. Harnack L, Walters S \& Jacobs Jr D (2003) Dietary intake and food sources of whole grains among US children and adolescents: data from the 1994-1996 Continuing Survey of Food Intakes by Individuals. J Am Diet Assoc 103, 1015-1019.

37. Alexy U, Clausen K \& Kersting M (2008) Die Ernährung gesunder Kinder und Jugendlicher nach dem Konzept der Optimierten Mischkost. Ernährungs Umschau 55, 168-177.

38. Remer T, Fonteyn N, Alexy U et al. (2006) Longitudinal examination of 24-h urinary iodine excretion in schoolchildren as a sensitive, hydration status-independent research tool for studying iodine status. Am J Clin Nutr 83, 639-646.

39. Russo GL (2009) Dietary $n-6$ and $n-3$ polyunsaturated fatty acids: from biochemistry to clinical implications in cardiovascular prevention. Biochem Pharmacol 77, 937-946.
40. Štimec M, Kobe H, Smole K et al. (2009) Adequate iodine intake of Slovenian adolescents is primarily attributed to excessive salt intake. Nutr Res 29, 888-896.

41. Valsta LM, Jauhiainen M, Aro A et al. (1992) Effects of a monounsaturated rapeseed oil and a polyunsaturated sunflower oil diet on lipoprotein levels in humans. Arterioscler Thromb 12, 50-57.

42. Södergren E, Gustafsson I-B, Basu S et al. (2001) A diet containing rapeseed oil-based fats does not increase lipid peroxidation in humans when compared to a diet rich in saturated fatty acids. Eur J Clin Nutr 55, 922-931.

43. Brownell KD, Farley T, Willett WC et al. (2009) The public health and economic benefits of taxing sugar-sweetened beverages. $N$ Engl J Med 361, 1599-1605.

44. Brownell KD \& Frieden TR (2009) Ounces of prevention the public policy case for taxes on sugared beverages. $N$ Engl J Med 360, 1805-1808.

45. Alexy U, Sichert-Hellert W, Kersting M et al. (2001) The foods most consumed by German children and adolescents: results of the DONALD Study. Dortmund Nutritional and Anthropometric Longitudinally Design. Ann Nutr Metab 45, 128-134. 